\title{
Haemostatic property of Chromolaena odorata leaf extracts: in vitro and in vivo evaluation in wistar rats
}

\author{
Henshaw Uchechi Okoroiwu, ${ }^{1}$ Item Justin Atangwho, ${ }^{2}$ Emmanuel Kufre Uko, ${ }^{1}$ \\ Okafor Ifeyinwa Maryann' \\ ${ }^{1}$ Department of Medical Laboratory Science, University of Calabar, Calabar; ${ }^{2}$ Department of \\ Biochemistry, University of Calabar, Calabar, Nigeria
}

\begin{abstract}
This study was designed to investigate the effects of aqueous, ethanol and crude extracts of Chromolaena odorata leaf on haemostatic mechanism of wistar rats and its possible in vitro use in coagulation study. Fifty wistar rats of both sexes weighing between 140-180 g were sorted into 10 groups each fed via oral gavage once daily for 21 days. Sample collection was done by cardiac puncture. Bleeding and clotting times were performed using Duke's and Ivy's methods, respectively. The prothrombin time was performed using the Quick's one
\end{abstract}

Correspondence: Henshaw Uchechi Okoroiwu, Haematology Unit, Department of Medical Laboratory Science, University of Calabar, Calabar, Nigeria.

Tel: +234-8038833901.

Email: okoroiwuhenshaw@gmail.com

Key words: Chromolaena odorata; Haemostatic activity; Haemostasis.

Contributions: $\mathrm{OHU}$ conceived the study; $\mathrm{OHU}$, AIJ and UEK are responsible for the experimental design; OHU, AIJ and OIM participated in the leaf extraction process; $\mathrm{OHU}$ AIJ participated in the laboratory analysis of the haemostatic activity; $\mathrm{OHU}$ performed the data analysis, and prepared the manuscript; UEK, OIM and AIJ edited the manuscript. All authors read and approved the final manuscript.

Acknowledgements: authors are grateful to Prof. P. Ebong, the Coordinator of Endocrine Research Laboratory, Biochemistry Department, University of Calabar for provision of working space and equipments and also Prof. A.A.A. Alaribe, the Head of Department, Medical Laboratory Science, University of Calabar for the approval to use equipment from the Postgraduate laboratory.

Conflict of interest: the authors declare no potential conflict of interest.

Received for publication: 29 July 2016.

Revision received: 7 October 2016.

Accepted for publication: 3 November 2016.

(C) Copyright U.O. Henshaw et al., 2016

Licensee PAGEPress, Italy

Journal of Biological Research 2016; 89:6211

doi:10.4081/jbr.2016.6211

This article is distributed under the terms of the Creative Commons Attribution Noncommercial License (by-nc 4.0) which permits any noncommercial use, distribution, and reproduction in any medium, provided the original author(s) and source are credited. stage method, while the partial thromboplastin time using kaolin was done using Macpherson and Hardity method using Giess diagnosis reagent. Significant results were observed in the bleeding and clotting times of the three extracts in a dose-dependent manner. The 300 $\mathrm{mg} / \mathrm{kg}$ ethanol extract decreased the bleeding time more than the other two extracts. Only the ethanol 150 and $300 \mathrm{mg} / \mathrm{mL}$ showed in vitro activity. The study showed the in vivo haemostatic properties of Chromolaena odorata leaf extracts and its possible use in in vitro coagulation study.

\section{Introduction}

The use of several plant parts such as leaves, barks, roots, for therapeutic purposes has been in practice in Africa since ancient times. ${ }^{1}$ The present trend in medicine is towards a change from the use of cellulose coated pills to extracts of plants supplied either in pure form or in synthetic version for curing human ailment. Thus, plants or plant parts may provide the basis for this modern therapeutics. ${ }^{1}$ Chromolaena odorata is a perennial scandent or woody shrub belonging to the Asteracaea family. In Nigeria it is called the Awolowo or Independent plant. ${ }^{2} \mathrm{~A}$ decoction of the leaf in traditional medicine is used as a cough remedy and as an ingredient with lemon grass and guava for the treatment of malaria. The juice pressed out of the crushed leaves is applied to cuts to stop bleeding as well as accelerates wound healing. ${ }^{2}$ Considering the current wider application of plant extracts in modern medicine, it becomes necessary to investigate the possible beneficial use of the pure and crude extracts of Chromolaena odorata in bleeding diathesis.

\section{Materials and Methods}

\section{Preparation of plant part}

Fresh Chromolaena odorata leaves were harvested from farms along University of Calabar staff quarters road and were identified by Dr. J.K. Ebigwai of Botany Department, University of Calabar. These were rinsed with distilled water and dried under shade. The dried leaves were ground into powder after which $200 \mathrm{~g}$ of the coarse powder was suspended in $1200 \mathrm{~mL}$ of ethanol (98.67\%BDH) and $1200 \mathrm{~mL}$ of distilled water for the ethanol and aqueous extractions, respectively and agitated thoroughly for about 10 minutes with an electric blender. The suspensions were allowed overnight in a Westcool fridge $\left(4^{\circ} \mathrm{C}\right)$. Twenty-four hours later, the mixtures were filtered with chess cloth and the filtrates concentrated in vacuo (rotary evapora- 
tor) to $10 \%$ of the original volume at $40^{\circ} \mathrm{C}$. These concentrates were kept in water bath at $37^{\circ} \mathrm{C}$ for complete dryness. These extracts were reconstituted in normal saline to an appropriate concentration before administration. ${ }^{3}$ Fresh leaves for the crude extraction were ground using manual grater followed by decoction and then gravimetric analysis. ${ }^{4}$

\section{Animal treatment}

A total of 50 apparently healthy wistar rats of both sexes weighing between 140-180 g obtained from the animal house College of Medical Sciences, University of Calabar were sorted for the haemostatic evaluation. All experimental animals were fed with standard animal feed and water ad libitum. All the experiments were performed in accordance with the guidelines for care and use of laboratory animals of Faculty Animal Research Ethics Committee (FAREC-FBMS) Faculty of Basic Medical Sciences University of Calabar. ${ }^{5}$ Animal use protocols were approved by the Faculty Animal Research Ethics Committee (FARECFBMS) Faculty of Basic Medical Sciences University of Calabar with reference number 001B4216.

\section{Phytochemical analysis}

\section{Test for alkaloids}

Presence of alkaloid in the extracts was estimated by Mayer's, Wagner' and Dragendorrf's tests. Each of the extracts was stirred with $1 \%$ aqueous hydrochloric acid on water bath and filtered. Two milliliters of the filtrates (in each case) were added to Mayer's reagent, Wagner's reagent and Dragendorrf's reagent in separate tubes. Alkaloids react with each of the reagents to form precipitate. The turbidity of the precipitation with either of the reagents is proportional to the quantity of alkaloid present. ${ }^{6}$

\section{Test for tannins}

Ferric Chloride and Lead Acetate tests were used to detect the presence of tannins. The extracts were stirred with distilled water and filtered. Two milliliters of the filtrates were then added to $10 \%$ ferric chloride and $10 \%$ lead acetate in separate tubes. Tannin in the extract reacts with the ferric chloride and lead acetate to form a blue-black, green or blue-green precipitate (in each case) ${ }^{6}$

\section{Test for saponnins}

Emulsifying and Frothing tests were used to detect the presence of Saponnins. The extracts were warmed with distilled water and filtered. Three drops of olive oil was added to $2 \mathrm{~mL}$ of the filtrate for the emulsifying test, while $4 \mathrm{~mL}$ of distilled water was added to $1 \mathrm{~mL}$ of the filtrate for the frothing test. Both were shaken. Presence of brown emulsion (for the emulsifying test) and frothing (for frothing test) confirmed presence of saponnins. ${ }^{6}$

\section{Test for anthraquinone}

Presence of anthraquinone was detected by modified Borntrager's test. Ten milliliters of concentrated chloroform was used to dissolve the extracts. The resulting solution was then filtered. Two and half milliliters of the filtrate was then added to $2.5 \mathrm{~mL}$ ammonia solution and shaken vigorously. Presence of pink to red precipitates confirmed the presence of anthraquinones. ${ }^{6}$

\section{Test for glycosides}

Half a gram of the extracts was boiled with $5 \mathrm{ml}$ of dilute hydrochloric acid and the resulting solution was neutralized with sodium hydroxide solution and filtered. Two milliliters of the resultant filtrate was then added to Fehlings solution 1 and 2, mixed thoroughly and boiled in water bath for 2 minutes. The appearance of reddish-brown precipitates indicated a positive result. ${ }^{6}$

\section{Test for flavonoids}

The presence of flavonoid in the extracts was determined by sodium hydroxide method. The extracts were dissolved in distilled water and filtered. Two milliliters of the resultant filtrate was then added to two different tubes. Three drops of sodium hydroxide were added to the first tube and allowed to stand for 2 minutes. Three drops of sodium hydroxide and 3 drops of $0.5 \mathrm{~N}$ hydrochloric acid were added to $2 \mathrm{~mL}$ of the filtrate in the second tube. Both mixtures were observed for precipitation and colour change. Production of yellow coloration in the first tube and transition from yellow to colourless in the second tube confirmed presence of flavonoids. ${ }^{6}$

\section{Study protocol}

The experimental animals were divided into ten groups and each group consisted of five animals. Group I served as control and received $0.2 \mathrm{~mL}$ of normal saline vehicle. Group II animals received $75 \mathrm{mg} / \mathrm{kg}$ of aqueous extract. Group III received $150 \mathrm{mg} / \mathrm{kg}$ of aqueous extract. Group IV received $300 \mathrm{mg} / \mathrm{kg}$ of aqueous extract. Group V received 75 $\mathrm{mg} / \mathrm{kg}$ of the ethanol extract. Group VI received $150 \mathrm{mg} / \mathrm{kg}$ of the ethanol extract. Group VII received $300 \mathrm{mg} / \mathrm{kg}$ of the ethanol extract. Group VIII received the $75 \mathrm{mg} / \mathrm{kg}$ of the crude extract. Group IX received $150 \mathrm{mg} / \mathrm{kg}$ of the crude extract. Group X received the $300 \mathrm{mg} / \mathrm{kg}$ of the crude extract. Extracts for the test groups were dissolved in normal saline vehicle with respect to their concentration (extract dry weight per kg of the animal weight) and animal body weight. All dosages above were administered once per day via oral gavage for 21 days.

\section{Sample collection and analysis}

At the end of the study period, Bleeding and Clotting Times were performed and the animals were sacrificed and blood collected via cardiac puncture into trisodium citrate container and analyzed immediately.

\section{Bleeding time}

The Bleeding Time was performed using Duke's method. The tip of the tail of each rat was cut with lancet to cause bleeding. Immediately the bleeding started, a stopwatch was started. Every 15 seconds, a blotting paper was used to wipe off blood and the stopwatch was stopped as soon as bleeding ceased. ${ }^{7}$

\section{Clotting time}

The Clotting Time was performed using Ivy's method. A drop of blood from the animal was placed on a clean grease free slide with a stopwatch started at the same time. Every 15 seconds, a pin was passed and the stopwatch stopped once thread of fibrin was noticed. ${ }^{7}$

\section{Prothrombin time}

The Prothrombin time was done using Quick's one stage method (Giesse Diagnostic reagent). Two and a quarter milliliters $(2.25 \mathrm{~mL})$ of blood was added to $0.25 \mathrm{~mL}$ of $3.2 \%$ trisodium citrate, mixed and centrifuged at $1000 \mathrm{~g}$ for 15 minutes to get platelet poor plasma. One hundred microlitres $(100 \mu \mathrm{L})$ of the citrated plasma was then added to a glass tube and incubated in a water bath at $37^{\circ} \mathrm{C}$ for 2 minutes. Two hundred microlitres $(200 \mu \mathrm{L})$ of thromboplastin was added and incubated for 1 minute followed by $100 \mu \mathrm{L}$ of calcium chloride. The stopwatch was started on addition of the calcium chloride and the tubes were tilted repeatedly into the water bath until a cloth was formed and the time was recorded. 


\section{Partial thromboplastin time with kaolin}

Partial thromboplastin time with kaolin was performed using the method of Macpherson and Hardity (1961) and Proctor and Rapoport (1961) (Giesse Diagnostic reagent). Two and a quarter milliliters (2.25 $\mathrm{mL}$ ) of blood was added to $0.25 \mathrm{~mL}$ of $3.2 \%$ trisodium citrate, mixed and centrifuged at $1000 \mathrm{~g}$ for 15 minutes to get platelet poor plasma. One hundred microlitres $(100 \mu \mathrm{L})$ of the citrated plasma was then added to $100 \mu \mathrm{L}$ of phospholipid reagent and incubated at $37^{\circ} \mathrm{C}$ for 3 minutes. After 3 minutes, $100 \mu \mathrm{L}$ of $0.25 \mathrm{~m}$ calcium chloride solution was added simultaneously putting on the stopwatch. Clotting was confirmed by tilting the tube in and out of the water bath.

\section{In vitro study}

The in vitro study was done following the Quick's one stage method of prothrombin time with the modification of substituting tissue thromboplastin with varying concentrations of the leaf extracts (75, 150 and $300 \mathrm{mg} / \mathrm{mL}$ of the three different extracts). The results of the prothrombin time of the different extracts were compared with that of standard thromboplastin reagent using same sample plasma. The dry aqueous and ethanol extracts were dissolved in normal saline.

\section{Statistical analysis}

All values were expressed as mean \pm standard error of mean. Statistical difference between groups were determined using one-way analysis of variance (ANOVA) followed by least significant difference test in significant cases using SPSS version 20 software. Differences were considered to be statistically significant when $\mathrm{P}<0.05$.

\section{Results}

The mean bleeding and clotting times of the aqueous extract were significantly $(\mathrm{P}<0.05)$ decreased along the varying dose line in a dose dependent manner whereas there were no significant difference in the values of the prothrombin time (PT) and partial thromboplastin time using kaolin of the control and test groups (Table 1).

In the same manner, both the Bleeding and Clotting Times of ethanolic extracts of Chromolaena odorata treated rats were significantly $(\mathrm{P}<0.05)$ decreased along the varying dose line in a dose dependent manner. There were no significant difference in the PT and PTTK of the test and control groups (Table 2). Similarly, the bleeding and clotting times of the crude Chromolaena odorata treated rats were significantly $(\mathrm{P}<0.05)$ decreased along the varying dose line in a dose dependent manner. There were no significant difference in the PT and PTTK of the test and control groups (Table 3). Comparatively the 300 $\mathrm{mg} / \mathrm{kg}$ ethanol extract decreased the bleeding time more than the other two extracts whereas the $300 \mathrm{mg} / \mathrm{kg}$ aqueous extract decreased the clotting time more than the other two extracts. Only the ethanol 150 and $300 \mathrm{mg} / \mathrm{mL}$ extracts of $C$. odarata leaf extracts showed in vitro activity with citrated plasma and calcium chloride (Table 4).

Table 1. Some haemostatic parameters of aqueous Chromolaena odorata extract treated rats.

\begin{tabular}{lcccc} 
Parameter & Control & $75 \mathrm{mg} / \mathrm{kg}$ & $150 \mathrm{mg} / \mathrm{kg}$ & $300 \mathrm{mg} / \mathrm{kg}$ \\
Bleeding time (sec) & $140.9 \pm 2.9$ & $67.9 \pm 5.3^{*}$ & $47.2^{*} \pm .7^{*}$ & $46.5 \pm 2.4^{*}$ \\
Clotting time (sec) & $132.4 \pm 2.8$ & $78.1 \pm 1.6^{*}$ & $69.8 \pm 3.4^{*}$ & $43.8 \pm 8.1^{*}$ \\
\hline PT (sec) & $20.5 \pm 1.5$ & $19.1 \pm 0.3$ & $18.3 \pm 0.3$ & $18.3 \pm 0.8$ \\
PTTK (sec) & $18.5 \pm 1.5$ & $23 \pm 1.3$ & $23.3 \pm 0.7$ & $25.3 \pm 4.0$ \\
\hline
\end{tabular}

PT, prothrombin time; PTTK, partial thromboplastin time with kaolin. Data are expressed as mean \pm standard error of mean. *Significant difference from control $(\mathrm{P}<0.05)$.

Table 2. Some haemostatic parameter of ethanolic Chromolaena odorata extract treated rats.

\begin{tabular}{lcccc}
\hline Parameter & Control & $75 \mathrm{mg} / \mathrm{kg}$ & $150 \mathrm{mg} / \mathrm{kg}$ & $300 \mathrm{mg} / \mathrm{kg}$ \\
Bleeding time (sec) & $140.9 \pm 2.9$ & $64.8 \pm 2.8^{*}$ & $55.8 \pm 3.1^{*}$ & $41.8 \pm 2.4^{*}$ \\
Clotting time (sec) & $132.4 \pm 2.8$ & $86.1 \pm 1.9^{*}$ & $84.1 \pm 1.8^{*}$ & $14.2 \pm 1.8^{*}$ \\
\hline PT (sec) & $20.5 \pm 1.5$ & $18.7 \pm 0.8$ & $17.5 \pm 1.3$ & $19.0 \pm 0.7$ \\
PTTK (sec) & $18.5 \pm 1.5$ & $27.7 \pm 3.1$ & $24.5 \pm 2.7$ & $23.3 \pm 1.3$ \\
\hline
\end{tabular}

PT, prothrombin time; PTTK, partial thromboplastin time with kaolin. Data are expressed as mean \pm standard error of mean. *Significant difference from control $(\mathrm{P}<0.05)$.

Table 3. Some haemostatic parameter of crude Chromolaena odorata extract treated rats.

\begin{tabular}{lcccc}
\hline Parameter & Control & $75 \mathrm{mg} / \mathrm{kg}$ & $150 \mathrm{mg} / \mathrm{kg}$ & $300 \mathrm{mg} / \mathrm{kg}$ \\
Bleeding time (sec) & $140.9 \pm 2.9$ & $93.2 \pm 5.0^{*}$ & $80.8 \pm 7.8^{*}$ & $63.8 \pm 3.1^{*}$ \\
Clotting time (sec) & $132.4 \pm 2.8$ & $106.6 \pm 1.2^{*}$ & $73.6 \pm 6.4^{*}$ & $67.2 \pm 0.3^{*}$ \\
\hline PT (sec) & $20.5 \pm 1.5$ & $19.0 \pm 0.7$ & $19.0 \pm 0.1$ & $18.5 \pm 0.5$ \\
PTTK (sec) & $18.5 \pm 1.5$ & $28.0 \pm 2.4$ & $18.5 \pm 0.5$ & $23.5 \pm 3.5$ \\
\hline
\end{tabular}

PT, prothrombin time; PTTK, partial thromboplastin time with kaolin. Data are expressed as mean \pm standard error of mean. *Significant difference from control $(\mathrm{P}<0.05)$. 
Table 4. In vitro coagulative properties of Chromolaena odorata.

\begin{tabular}{|c|c|c|c|c|c|c|c|c|}
\hline & Thromboplastin & $\mathrm{AQ75}$ & $\mathrm{AQ150}$ & $\mathrm{AQ300}$ & ETH75 & ETH150 & ETH300 & Crude \\
\hline \multirow[t]{9}{*}{ PT (min) } & 0.25 & $>10$ & $>10$ & $>10$ & $>10$ & 4.5 & 5.6 & $>10$ \\
\hline & 0.30 & $>10$ & $>10$ & $>10$ & $>10$ & 4.8 & 6.1 & $>10$ \\
\hline & 0.20 & $>10$ & $>10$ & $>10$ & $>10$ & 4.6 & 5.5 & $>10$ \\
\hline & 0.25 & $>10$ & $>10$ & $>10$ & $>10$ & 4.6 & 5.1 & $>10$ \\
\hline & 0.22 & $>10$ & $>10$ & $>10$ & $>10$ & 4.5 & 6.1 & $>10$ \\
\hline & 0.16 & $>10$ & $>10$ & $>10$ & $>10$ & 5.5 & 6.2 & $>10$ \\
\hline & 0.22 & $>10$ & $>10$ & $>10$ & $>10$ & 5.6 & 6.3 & $>10$ \\
\hline & 0.27 & $>10$ & $>10$ & $>10$ & $>10$ & 5.9 & 6.2 & $>10$ \\
\hline & 0.23 & $>10$ & $>10$ & $>10$ & $>10$ & 4.6 & 5.7 & $>10$ \\
\hline
\end{tabular}

$\mathrm{AQ}$, aqueous; ETH, ethanol.

\section{Discussion}

Bleeding time evaluates the vascular and platelet response with homeostasis, ${ }^{8,9}$ while clotting time is a qualitative measurement of factors involved in the intrinsic pathway. ${ }^{8,10}$ This study was focused on determining the effects of Chromolaena odorata on haemostatic mechanism with specific interest on how it affects the bleeding time, clotting time, prothrombin time and partial thromboplastin time with kaolin. In this study, the three different extracts of Chromolaena odorata significantly decreased the bleeding time. This observation is a suggestion of effects on capillary integrity or platelet. ${ }^{8,9}$ The observation is in consonance with findings of Akomas and Ijioma (2004), ${ }^{11}$ who reported a reduction in bleeding time using ethanol extract of Chromolaena odor$a t a$. This study showed significant reduction in the clotting time in all the various extracts in their varying doses. This result is a suggestion of the increase in one or more of the clotting factors of the intrinsic pathway. ${ }^{8,10}$ This observation is in line with earlier submission by Akomas and Ijioma (2004) $)^{11}$ who had earlier reported the potential of Chromolaena odorata in reducing clotting time. The haemostatic property of $C$. odorata has been attributed to the presence of tannins and saponnins in the leaf extracts. Tannins have been implicated in the haemostatic activity of plants where they arrest bleeding from damaged or injured vessels by precipitating proteins to form vascular plugs. More so, saponnins have been reported to have precipitating and coagulative properties. The result of this study coupled with increased mean platelet volume (MPV) in the aqueous extract and results from previous studies $^{12-14}$ suggested that the haemostatic property of Chromolaena odorata is mostly from the platelet activity/quality rather than quantity or clotting factors. This was further corroborated by the insignificant difference in the PT and PTTK of the test and control groups ruling out significant contributions from clotting factors. The increased mean platelet volume in the aqueous leaf extract is an indication of an improved platelet quality. Further changes in MPV appear to play more roles in haemostasis than platelet count. ${ }^{14} \mathrm{An}$ increased mean platelet volume is an indication of larger and more reactive platelet resulting from increased platelet turnover. Large platelets are more adhesive and tend to aggregate more than smaller platelets and contain more secretary granules and mitochondria and known to be more active than smaller ones. ${ }^{15}$ This submission is corroborated by earlier reports by Hataichariok et al. (2013) ${ }^{16}$ who attributed the haemostatic property of $C$. odorata to improved platelet aggregation. Only the ethanol 150 and $300 \mathrm{mg} / \mathrm{mL}$ showed promising in vitro activity as alternative laboratory reagent for coagulation studies in the laboratory.

\section{Conclusions}

The various leaf extracts significantly reduced the bleeding and clotting times of the experimental animals in a dose-dependent manner establishing the haemostatic property of Chromolaena odorata leaf extracts. The result of this study in synergy with earlier reports shows that the role of Chromolaena odorata in haemostasis is towards improved platelet function rather than platelet count and effect on clotting factors. This result suggests the possible incorporation of the leave extracts of Chromolaena odorata in bleeding diathesis as well as in coagulation studies. This study has pioneered the comparative haemostatic activities on different extracts of Chromolaena odorata leaf.

\section{References}

1. Suriyavathana M, Parameswam G, Shiyan S. Biochemical and antimicrobial study of Boerhavin erecta and Chromolaena Odorata (L.). King and Robinson. Int J Pharm Sci Res 2012;3:465-68.

2. Inyang CU, Adegoke AA. Antimicrobial properties and preliminary phytochemical screening of Chormolaena odorata (Siam or Sapysa weed). Nig J Microbiol 2008;22:1652-59.

3. Atangwho IJ, Ebong PE, Eteng MU, Eyong EU. Effects of Vernonia Amygdalina Del. on liver function in Alloxan induced hyperglycemic rats. Int J Pharmacol 2007;3:143-4.

4. Harvey DI. Modern analyical chemistry. Boston: McGraw-Hill; 2000.

5. FAREC-FBMS. Guidelines on the care and use of animals for scientific research purpose. Calabar: Faculty Animal Research Ethics Committee, Faculty of Basic Medical Sciences, University of Calabar; 2015.

6. Trease EC, Evans WC. Pharmacognosy, $12^{\text {th }}$ ed. London: Bailliere and Tindall; 1983.

7. Ibu J0, Adeniyi KO. A manual of practical physiology. Jos: Jos University press; 1989.

8. Dapper DV, Achinike PN, Gwotmut MD. Effects of aloe vera (gel) on clotting time, prothrombin time and plasma fibrinogen concentration in albino wister rats. Port Harcourt Med J 2007;2:56-60.

9. Weremfo A, Adenortey MB, Pappoe AN. Advances in biological research. 2000; 5:190-92.

10. Ochei J, Kolhatkar A. Medical laboratory science theory and practice. New Delhi: Tata Mcgraw-Hill Publishing Company; 2000.

11. Akomas SC, Ijioma SN. Bleeding and clotting time effects of 
ethanol extract of Chromolaena odorata versus Ocimum gratissimum treated Albino rats. Comp J Med Sci 2014;2:9-13.

12. Anyasor GN, Aina DA, Olushola M, Aniyikaye AF. Phytochemical constituents, proximate analysis, antimicrobial and wound healing properties of extract of Chromolaena odorata. Ann Biol Res 2011; 2:441-51.

13. Okoli CO, Akah PA, Okoli AS. Potential of leaves of Aspilia africa (composites) in wound care; an experimental evaluation. BMC Compl Altern Med 2007;7:24:10.
14. Kavitha V, Mohamed S, Maruthi R. Studies on phytochemical screening and antioxidant activity of Chromolaena Odorata and Annona squamosa. Int J Innov Res 2013;2:7315-21.

15. Martin JF, Plumbs J, Kilbey RS, Kish YT. Changes in volume and density of platelets in myocardial infarction. Brit Med $\mathrm{J}$ 1983;287:456-9.

16. Hataichanok P, Xiaobo Z, Jason L. Haemostatic and wound healing properties of Chromolaena odorata leaf extracts. ISRN Derm 2013;2013:168269. 